\title{
Virtual Synchronous Generator: Laboratory Scale Results and Field Demonstration
}

\author{
Vu Van Thong, Achim Woyte, Mihaela Albu, Marcel Van Hest, Jan Bozelie, Javier Diaz, Tom Loix, \\ Dan Stanculescu, Klaas Visscher
}

\begin{abstract}
This paper describes an approach to demonstrate the operation of virtual synchronous generators (VSG) in practical distribution systems. After an extensive simulation phase at laboratory scale, the field demonstration is planned at two sites located in the Netherlands and in Romania, for small VSGs of $10 \times 5 \mathrm{~kW}$ and one large VSG of $100 \mathrm{~kW}$ respectively.
\end{abstract}

Index Terms- Virtual Synchronous Generator, Demonstration, Inertia, Microgrid, Storage

\section{INTRODUCTION}

$\mathrm{T}$ HE stability of power systems is traditionally achieved by regulating large synchronous machines with high inertia to accommodate various disturbances in power systems. With the increase share of many small distributed generators (DG) having small or no inertia, the power generation from large synchronous generation will be reduced. Many large units will be shut down at low load periods due to economic and technical reasons as they cannot operate lower than at some minimum power settings. This causes a reduction of the system inertia, resulting in large frequency oscillations in cases of severe disturbances $[1,2]$. A solution towards stabilizing such a power system with dynamic shape is to provide additional virtual rotational inertias. Principally, this can be attained by adding short-term energy storage to any DG unit together with an intelligent control of the interface to the grid. The DG unit will then operate like a virtual synchronous generator (VSG), exhibiting some of the desired properties of synchronous machines for short time intervals.

The idea of a virtual synchronous machine is put into practice in the VSYNC project [3-6]. In order to successfully demonstrate the VSG concept, a significant part of work is allocated to the laboratory set-up and experimentation,

This work is a part of the VSYNC project funded by the European Commission under the FP6 framework with the contract No: FP6 - 038584 (www.vsync.eu).

V.V. Thong and A. Woyte are with 3E, Vaartstraat 61, B-1000, Brussels, Belgium (tel: $\quad+32-2-22958$ 68; e-mail: thong.vuvan@3e.eu, achim.woyte@3e.eu); M. Albu is with Politehnica University of Bucharest; J. Diaz is with Ufe; M. V. Hest and J. Bozelie are with Liandon; T. Loix is with KULeuven; D. Stanculescu is with Electrica; K. Visscher is with ECN, the Netherlands (e-mail: visscher@ecn.nl). including testing various control techniques operating on different types of short-term storage systems. Then, the field operation of large and small VSG systems will be demonstrated.

This paper aims at describing in detail the demonstration approach for the VSGs in order to bring the model from laboratory into practice. One demonstration site of 10 VSGs of $5 \mathrm{~kW}$ each in the Netherlands, and one demonstration site of one VSG of $100 \mathrm{~kW}$ in Romania are currently in preparation [6].

\section{LABORATORY SCALE EXPERIMENTS}

For testing and validation of different control algorithms as applied to various converters and storage solutions the VSG is first developed in the laboratory at a power scale of 5 to 10 $\mathrm{kW}$ per unit. The control algorithms of VSG are developed within the Matlab/Simulink environment, using Real-Time Workshop facility to implement the control algorithms on a development platform in a so-called "rapid development cycle" [8]. The VSG consists of a power electronic converter, short-term energy storage and a VSG control algorithm. For testing the solutions obtained in the numerical simulation phase, a flexible power electronics converter providing high versatility in both configuration and control is used [8].

\section{PREPARATION OF DEMONSTRATION}

\section{A. Experiments within distribution grids}

The idea of VSG, although proven as feasible during simulations, has still to be successful demonstrated as applied to real generators equipped with an appropriate designed VSG.

The most promising algorithms, approved for use in the field tests, suitable converter prototypes of VSG and shortterm energy stores will be used in the field test equipment in order to prove the VSG feasibility. The demonstration of VSG is planned to be carried out at the level of individual owners of distributed generators as well as on the level of tens of low power generators, as for example in residential areas.

The equipment of these two demonstration sites will be installed and embedded to the existing distribution systems. In order not to interfere and harm the security of existing distribution systems, careful testing before commissioning will 
be carried out. The VSG systems will be monitored and data are collected for further analysis and evaluation.

\section{B. Selection Criteria of Test Sites}

Site selection for field demonstration is important for successful tests. These are criteria of site selection:

- Can carry out as many test cases as possible without or with less harming to customers;

- Compatible with the size of VSG, as the site is too big, we cannot distinguish and see contributions from VSG;

- Can test with different control algorithms, functioning of VSG;

- Easy to access of transport for equipment of few tons;

- Within constraints of budget and time schedule of the VSYNC project.

Taking into consideration of these criteria, a site at Bronsbergen in the Netherland and a site in Cheia in Romania are chosen.

\section{Bronsbergen site:}

This is a holiday park with about 208 houses. There are 148 cottages with PV roofs of over $3 \mathrm{~kW}$ capacity each, $466 \mathrm{kWp}$ in total. The whole system is supplied from a transformer to four feeders (Fig. 1). Peak load is $150 \mathrm{~kW}$. Two large $200 \mathrm{~kW}$ inverters with a $375 \mathrm{KW}$ lead-acid battery system $\left(720 \mathrm{~V}^{*}\right.$ $5 \mathrm{Ah})$ are connected to the system.

10 VSGs of $5 \mathrm{~kW}$ each will be installed at 10 houses in the system.

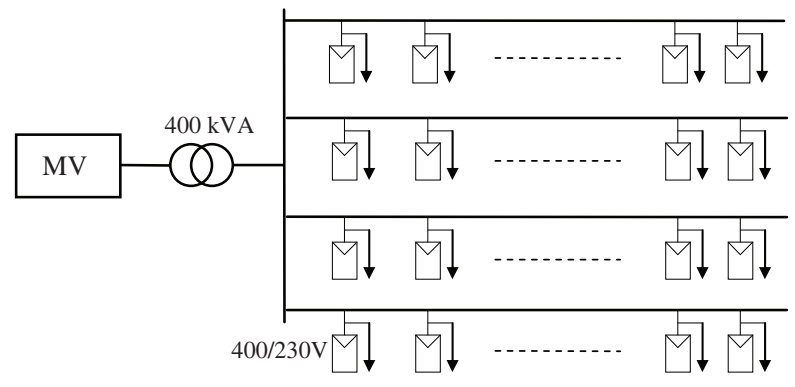

Fig. 1. Field test diagram in Bronsbergen

\section{Cheia site:}

A test site at Cheia is chosen. It locates about $140 \mathrm{~km}$ North of Bucharest, accessible for transport of the demonstration equipment. The low voltage system is supplied by a $20 \mathrm{kV} / 0.4$ $\mathrm{kV}$ transformer to five feeders (Fig. 2). The load is mainly residential. One VSG of $100 \mathrm{~kW}$ is connected to a reserved feeder at the low voltage side of the substation. An emulating DC voltage distributed generator is considered to install in this test site (the diode rectifier, figure 2), interfaced with an inverter. A short-term storage system (lead-acid rechargeable batteries) is added to the structure of the VSG. Field test set-up for installing the VSG in Cheia is illustrated in Fig. 3.

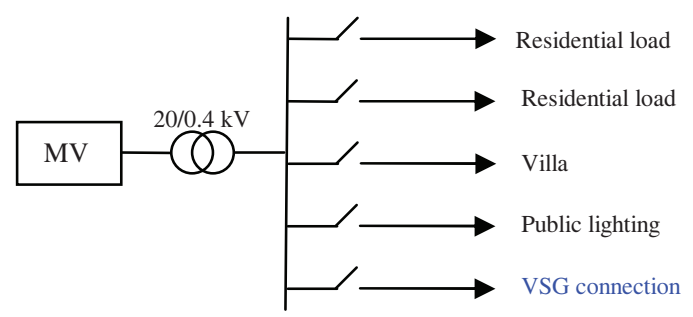

Fig. 2. Test site for a large VSG in Cheia, Romania

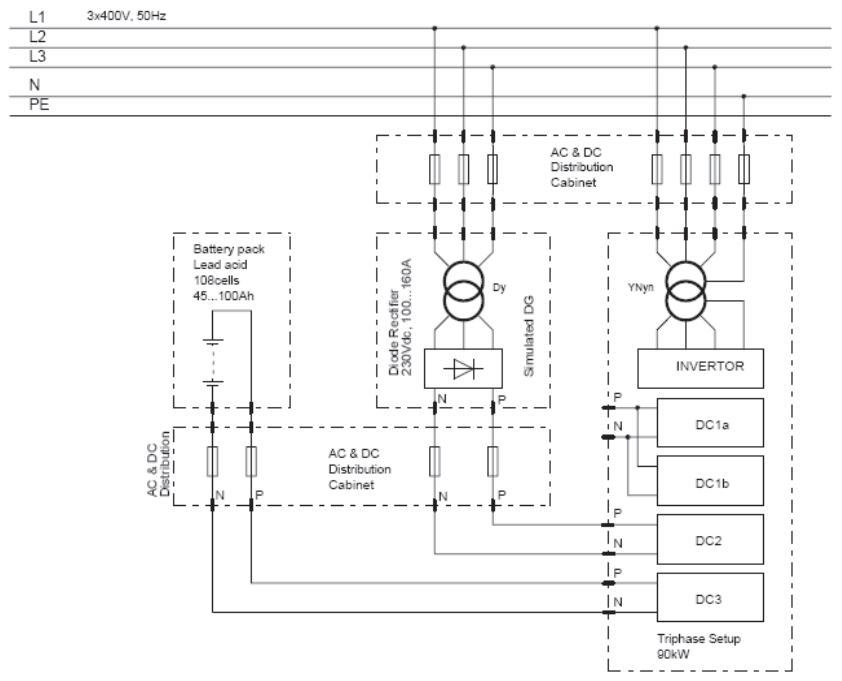

Fig. 3. Field test set-up for installing the VSG in Cheia, Romania

\section{Monitoring Data and Equipment}

\section{1) Monitoring strategy}

We plan to monitor field demonstrations for about one year. To collect all necessary data at high resolution is impossible since we need large storage capacity. Therefore, time intervals of data recording are as follow:

- Normal operation during the full demonstration period (without faults or large disturbances): measurement of standard operation parameters with 10-min average (I, V, f)

- High-speed sampling in case of specific events:

- Abnormal operation conditions, during disturbances or faults: trigger high speed sampling and transient recording at high resolution

- During detailed testing on site, also trigger transient recording

A data logger with adequate sensors, a power analyzer or a MOT will be installed at test sites to collect data.

Fig. 4 and Fig. 5 show the voltages and frequency during first 16 hours, as recorded in Cheia during $16^{\text {th }}$ of March 2009. Fig. 6 shows the average (on a 10 minutes interval) frequency, for the same day (a) and for the week 16-23 march 2009 (b). 


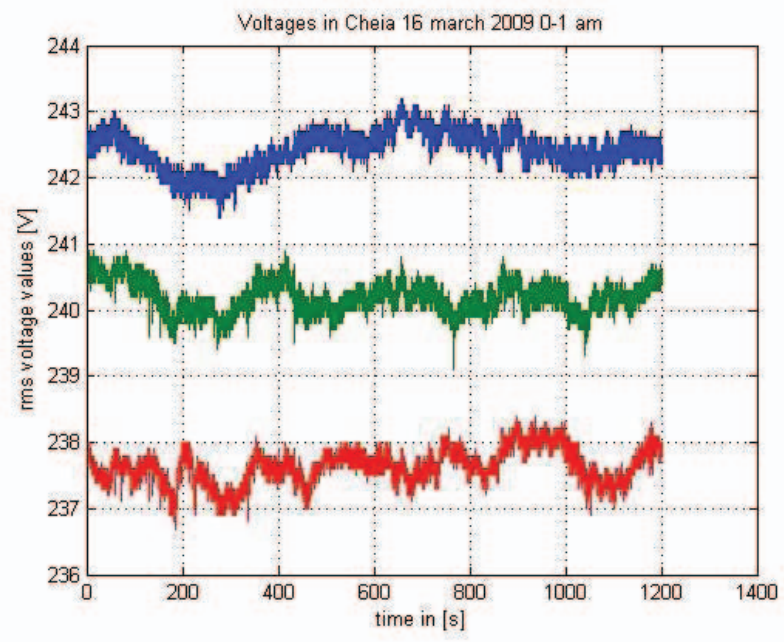

Fig. 4. Voltage in Cheia, Romania, on $16^{\text {th }}$ March 2009

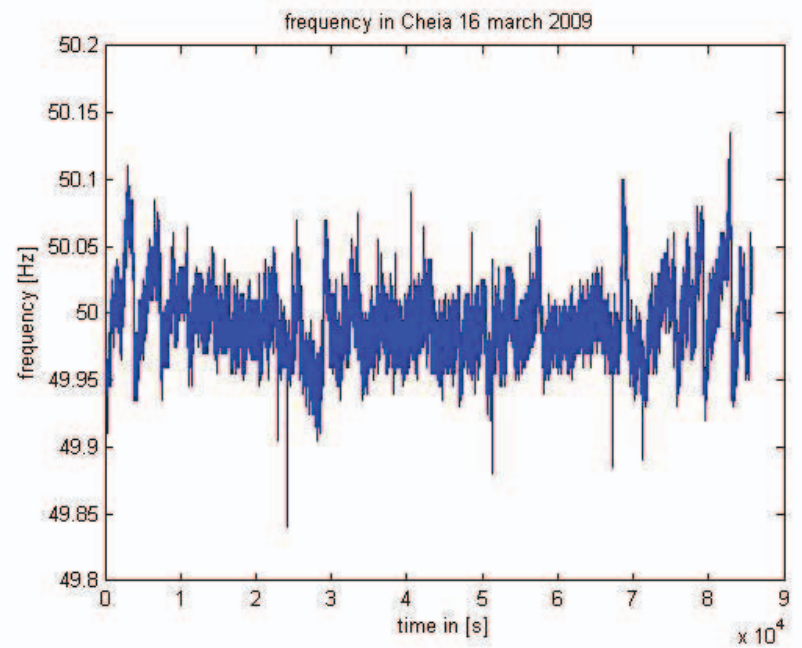

Fig. 5. Frequency in Cheia, Romania, on $16^{\text {th }}$ March 2009: 16 hours values;

\section{2) Monitoring equipment}

Power data logger:

It is a power data logger made by UfE, a partner of the VSYNC consortium. The monitoring equipment is a PC-based four-channel recorder at $16 \mathrm{bits} / 44.1 \mathrm{kHz}$ resolution. The channels can be used for monitoring voltages (rms values up to 270 V) or current (up to 20/200A). Data retrieving will be done with internet connection any time. Therefore, a good bandwidth is needed. This equipment is planned to install at the Bronsbergen site.

\section{Description of MOT}

MOT (Voltage monitoring equipment) is already installed in Cheia, Romania with a dedicated computer. It monitors continuous half-cycle-rms voltage waveforms registration. From acquired data the frequency will be also derived and aggregated according to the IEC 6100-4-30.

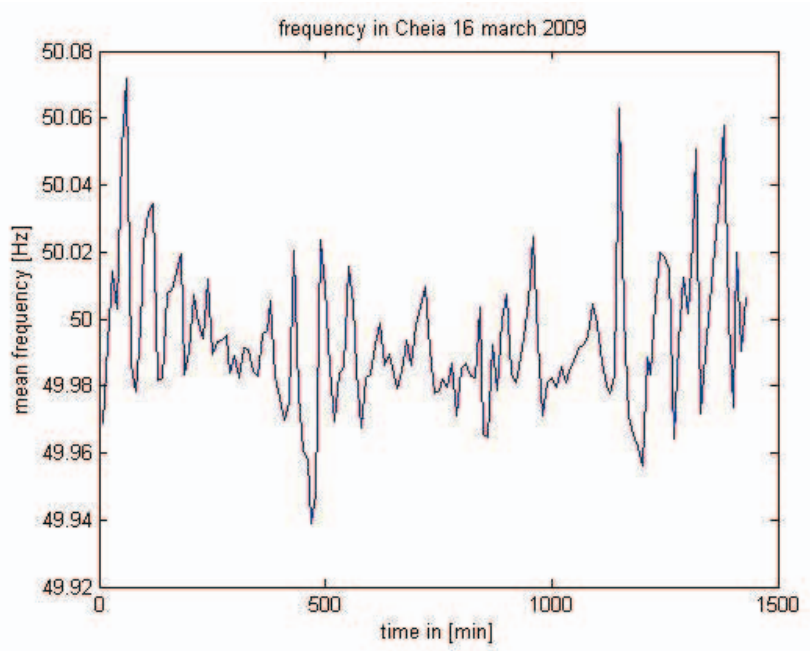

a)

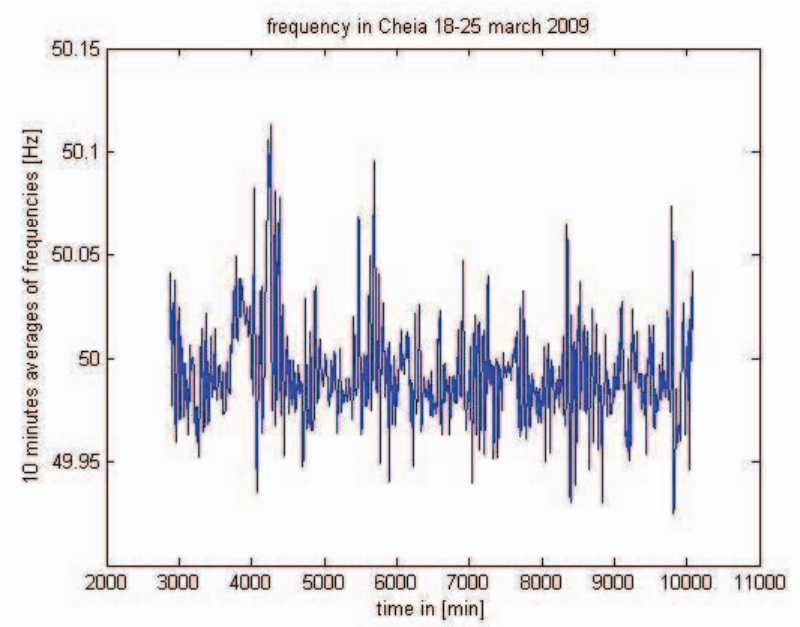

b)

Fig. 6. Frequency in Cheia 10 minutes average values: a) on 16 march 2009; b) - during the week 18-25 march 2009.

\section{Safety monitoring equipment:}

Regarding safety issues, other equipment of UfE is the ENS system, which prevents uncontrolled islanding effect following a failure or shutdown of the electricity supply, will be considered to install. This was proposed to test in practice at the Bronsbergen site. However, the ENS system needs to meet the network operation safety.

\section{D. $\quad$ SSG Inverters}

\section{1) Small-size VSG inverter}

This inverter is planned to test at the Bronsbergen site. It has power of $5 \mathrm{~kW}$, AC voltage output of $230 \mathrm{~V}$, and DC voltage input 48-60 V (Fig. 6). Ethernet connection for the DAQ and for the Laptop is required. This allows data retrieving and access to some features of the inverter from internet.

The hardware platform has its own internal control unit. It is in charge of the control of the inverter at low level (IGBTs switching, current/voltage measurement, over current/voltage protection, serial communication, etc.). 


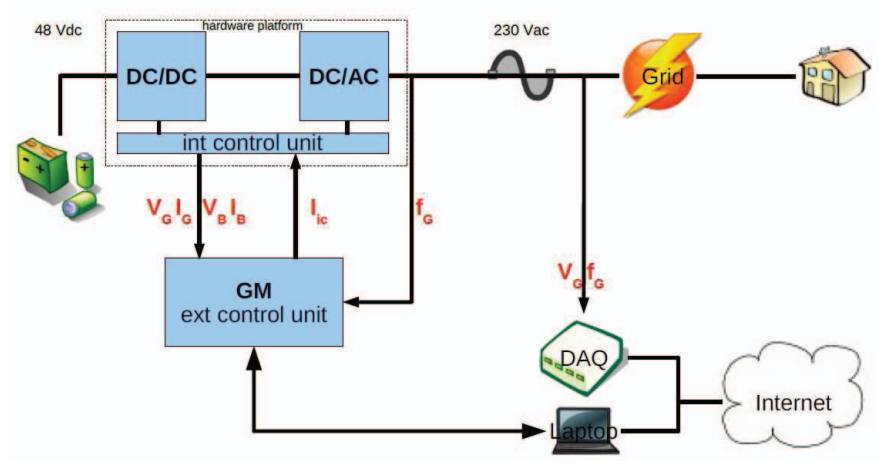

Fig. 6. Schema of Ufe's inverter, $5 \mathrm{~kW}$

The control of the inverter at high level is performed by the GM unit. Based on grid voltage and current, battery voltage and current and grid frequency, it is in charge of control the current that go from/to the DC side (battery system) and respectively to/from the $\mathrm{AC}$ side (grid). The control algorithm will let the inverter behave as a VSG.

\section{2) Medium-size VSG inverter}

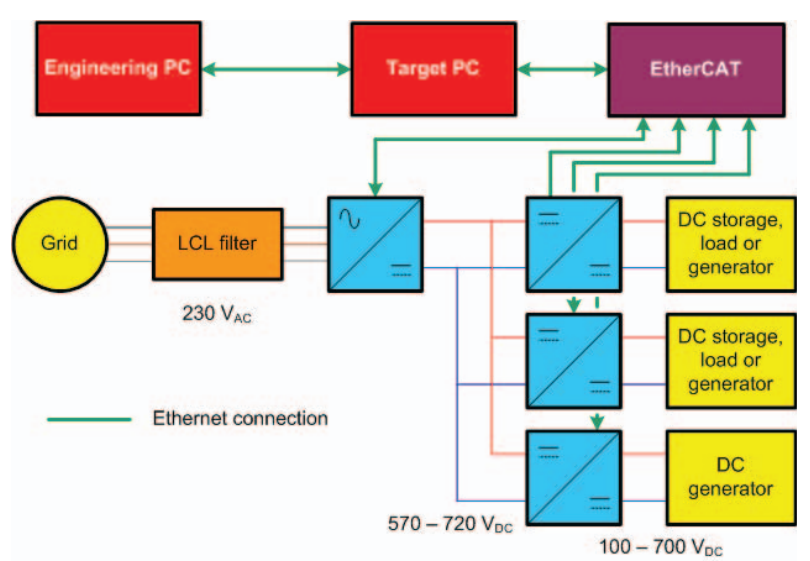

Fig. 7. Schema of Triphase's inverter, $5 \mathrm{~kW}$

The Triphase inverter cabinet contains two three-leg inverters, allowing the use of one three-phase four-leg gridconnected AC-DC inverter (with actively controlled neutral conductor), two bidirectional DC-DC converters (hardware for Buck converter setup present in the cabinet) and one bidirectional DC-DC convertor (using the IGBTs and antiparallel diodes of the break choppers of both inverters), fit for connection of a DC source. Communication between the inverters, measurement sensors and contactors on one hand and the Target PC on the other hand is done using the EtherCAT field bus system, which uses Ethernet communication. The user works on the Engineering PC, which can be connected to the Target PC. The inverter control scheme runs on the Target PC. The user can read out measurements, change control set-points and parameters, switch contactors, etc. by entering them on the Engineering PC and sending them to the Target PC, which interacts with the inverter cabinet through the EtherCAT interface.

\section{E. Generation of Disturbances}

It is impossible to validate and test performances of VSG without disturbances. A question is that we should create (generate) disturbances or wait for them to happen naturally. For the former case, we can only generate situations we have known but we can almost handle any problem and create disturbances at many times. For the later case, we have to wait for it and some unexpected situations (disturbances) to happen. If VSG can work well with expected and unexpected situations, we will claim that VSG operation is verified.

In parallel with normal operation, it is suggested to test with generated events and let the system operate and control with any natural incident. All necessary data for further analysis are recorded. Some possible generated events are:

- Switching on/off generators;

- Large demand variations;

- Change setting of large inverters;

- Create a short circuit;

- Introduction of power quality events (sags, etc).

\section{FIELD DEMONSTRATIONS}

\section{A. Demonstration Cases}

The simulation cases of VSGs for frequency stabilization were mentioned in [7]. This paper will describe how to implement field demonstration of VSG in the field. This may be used as a reference document for the field tests. Five Application Cases are chosen accordingly to their relevance for various DG use in practice. The tests are highly dependent on the DG type considered.

\section{1) Balancing Power - Frequency Control}

The power balancing problem is indeed a frequency control problem. In the definition of different test cases, we would test an isolate small grid with wind turbines and one central generator as a scalable of a future grid with significant intermittent generation (wind, PV, CHP).

Frequency control via fast active power regulation:

The frequency control function of the VSG will be demonstrated in combination with islanding operation testing since we cannot see much frequency variation with a large connected power system.

In the test site in Cheia, there is neither variable power source nor DG unit in the LV system. A procedure for this test will be done as following:

- The frequency will oscillate significantly after disconnecting the distribution segment (not yet hosting the VSG). Firstly a database with frequency variations recorded at high resolution in the network under test is completed, in order to determine how fast the VSG should react with large frequency disturbances.

- The needed virtual rotational inertia is then calculated, put into the VSG algorithms, and next the VSG is activated in order to verify its frequency stabilizing properties, and further fine-tune to optimal behavior. 
For the test site at Bronsbergen, these tests are carried out:

- Scenario 1: no VSG, then we will monitor if the system goes into critical condition than tripping all generator due to frequency instability

- Scenario 2: VSG contributes to the variable power source (PV) by buffering for a short time period, then the balancing is held for certain period (depending on the battery capacitor).

\section{2) Safety and Security of Power Supply}

The purpose of this test case is to see how VSG contributes to voltage compensation during a short circuit in order to reduce voltage dip (like rotating machines inject reactive power to the system during a fault). Due to small in size and normally connected to LV system, PV or CHP systems with inverters are planned for this test.

A short circuit is created on a distribution feeder (transformer) to have a significant voltage drops or the voltage drop is created by controlling voltage setting of large inverters. If we have VSG, it will buffer to slow down voltage drop to make sure PV inverters do not trip before safety devices kick in and fault is clear. It is necessary to guarantee not tripping DG units in healthy parts.

In the case there is no PV inverter or DG unit in the test sites, we can still carry out this test. Then voltage dip is recorded then comparing with and without VSG contributions.

In this test voltage and current are monitored by a power quality analyzer.

\section{3) Microgrid Operation}

For some reason the micro grid is disconnected from the main grid for several minutes. Without VSG the power balanced cannot be maintained, and DG units are possibly tripped.

\section{Intentional islanding}

The intentional islanding of VSG systems will be demonstrated. The duration of islanding operation will depend on the size of storage systems, which in this case will be selected to maintain energy balance of the tested network for 2-15 min, depending on the size of storage systems. The control algorithms for islanding mode and grid-connected mode are different, as the islanding system (micro-grid) has to define its own frequency and voltage to maintain safety operation. The performances of VSG control algorithms in both situations are monitored.

Both voltage and frequency at high resolution are recorded. Current flows through load, sources (PV) and VSG are recorded.

Several questions need to be clarified before testing such as procedure to start microgrid operation, installed monitoring equipment, duration of islanding and testing and in which loading condition.

\section{4) Reconnection of Microgrid}

The distribution system segment that was used to test islanding operation is then resynchronized to the main grid.

Two cases are foreseen for demonstration:

- The micro-grid (in terms of VSG sizing) remains in operation after disconnecting from the main grid for several minutes. Then frequency and voltage of the micro-grid are controlled in order to resynchronize with the main grid.

- Black-start: starting up the VSG from unloaded to the voltage and frequency references, then connecting gradually loads of micro-grid. The final step is synchronization with the main grid when the voltage and frequency are within the accepted ranges.

Monitoring parameters are similar to the case 3 (microgrid).

\section{5) Coordination of Storage System}

The purpose of this test is to coordinate different VSGs and DSO in order to maintain power balance for an optimal duration. As during periods of lack of power the VSG's can provide power from their stores to establish the power balance. If this condition is continued, without corrective measures being taken, the stores may get exhausted quickly. Power transferred of VSGs, durations of charge/discharge are monitored.

\section{CONCLUSIONS}

A field demonstration approach of the virtual synchronous machine is described in this paper. Description of site selection, concept of VSG, inverters, monitoring strategy and disturbance generation are given. Five different test cases are proposed. Due to some delay of VSG installation, there is no field demonstration result yet. However, the results will be put on the website (publication) or reports of the VSYNC project.

\section{ACKNOWLEDGMENT}

This work is a part of the VSYNC project funded by the European Commission under the FP6 framework with the contract $\mathrm{N}^{\mathrm{o}}$ : FP6 - 038584 (www.vsync.eu). The authors would like to thank other partners in the VSYNC consortium for their support and collaboration.

\section{REFERENCES}

[1] Vu Van T., Van Dommelen D.M., Belmans R.: " Penetration level of distributed energy resources with anti-islanding criteria and secure operation of power system," 2006 IEEE Power Engineering Society General Meeting, Montreal, Canada, June 18-22, 2006; 7 pages.

[2] Vu Van T.: "Impact of distributed generation on power system operation and control," K.U.Leuven, ESAT-ELECTA, Promotor: R.Belmans \& D.Van Dommelen, Assessor: Driesen J., ISBN 90-5682-717-0/UDC 621.315+621.316, May 29, 2006; 163 pages.

[3] VSYNC project - Virtual Synchronous Machines (VSG's) For Frequency Stabilisation In Future Grids With A Significant Share Of Decentralized Generation. http://www.vsync.eu (accessed 30/10/2008).

[4] J. Driesen, K. Visscher, Virtual synchronous generators, 2008, Proceedings of the IEEE PES Meeting, 20-24 July, Pittsburgh, PA, USA

[5] K. Visscher, S.W.H. de Haan, "Virtual synchronous machines for frequency stabilisation in future grids with a significant share of 
decentralised generation", 2008, Proceedings of the CIRED SmartGrids conference, 23-24 June, Frankfurt .

[6] K. Visscher, "VSYNC, The Virtual Synchronous Generator concept", (http://www.vsync.eu/fileadmin/vsync/user/docs/20080728-VSYNCGeneral_presentation.pdf)

[7] S. de Haan, K. Visscher: "Modelling and control of virtual synchronous machine," internal project report, August 2008 (14 pages)

[8] Triphase: http://www.triphase.com/

\section{BIOGRAPHIES}

Vu Van Thong (SM'02) received the B.E. and the M.E. degrees in Electrical Power Systems at Hanoi University of Technology, Vietnam in 1997 and Asian Institute of Technology, Thailand in 2001 respectively. He obtained his $\mathrm{PhD}$ in Engineering at the Katholieke Universiteit Leuven (Belgium) in 2006. $\mathrm{He}$ is working now as an expert for renewable energy in power systems and power markets at Energy Strategy unit, 3E n/v, Belgium.

Achim Woyte obtained his Electrical Engineering degree at the University of Hannover (Germany) in 1997 and his $\mathrm{PhD}$ in Engineering at the Katholieke Universiteit Leuven (Belgium) in 2003. Currently, he is working at 3E n/v as a reference expert for renewables in power systems and power markets and for photovoltaics, and responsible for international $R \& D$ co-operation and strategic relationships.

Mihaela Albu (M'96-SM'07) is from Craiova, Romania. She graduated from "Politehnica" University of Bucharest in 1987 and holds the Ph.D. degree (1998) from the same university. Since 2002 she is a Professor of Electrical Engineering. Her research interests include active distribution networks, DC grids, power quality, instrumentation, and remote experimentation embedded within on-line laboratories. Dr. Albu was spending a leave at Arizona State University as a Fulbright Fellow 2002 2003.
Marcel Van Hest is a consultant at Liandon, the Netherland.

Jan Bozelie is a consultant at Liandon, the Netherland.

Javier Diaz obtained his bachelor degree in Electrical Engineering at the National University (Colombia) in 1998 and his MSc in Electrical Engineering at the Darmstadt University of Applied Sciences (Germany) in 2008. Currently, he works in the development department of UfE $\mathrm{GmbH}$, Germany.

Tom Loix received the M.Sc. degree in Electrical Engineering from the K.U. Leuven, Belgium, in 2005. He is currently pursuing a Ph.D. degree in Electrical Engineering at the ELECTA research group from the K.U. Leuven. His main research interests are the control of grid-connected inverters, microgrids, uninterruptible power supplies and inverter output filter design.

Dan Stanculescu is a power systems expert at Electrica, a power distribution company in Romania.

Klaas Visscher received his Master's degree in 1988 and his Doctor's degree in 1993, both in Applied Physics at Twente University in The Netherlands. Next he worked several years on automation projects in his own consultancy. In 1999 he joined the Energy Research Centre of The Netherlands, where he first worked on heat storage and thermal processes for renewable energy applications for three years. In 2003 he joined the Intelligent Energy Grids program of ECN, working in the field of distributed power generation. As research co-ordinator Grid Connection and Power Quality in the ECN Intelligent Energy Grids program, the main topics of his current research are control and stability of distributed electricity generation systems in future grids. 